\title{
Indigenous images of a colonial exotic: imaginings from Bushman southern Africa
}

\author{
Sven Ouzman \\ Anthropology, 232 Kroeber Hall, University of California at Berkeley, CA 94720-3710, USA \\ \& Rock Art Department, National Museum, South Africa \\ ouzman@uclink.berkeley.edu
}

\section{Keywords}

Southern Africa, Bushman, reverse gaze, colonialism.

\begin{abstract}
Rock-art is a powerful and theoretically informed artefact that allows non-rock-art producing people an understanding of the worldview of the rock-artists. But the flow of information in such rock-art researches 'us' observing 'them' via 'their' artefacts is often asymmetrical and can be disempowering to the rock-artproducing individuals and communities past and present. Fortunately, rock-art is also able to balance and even reverse this asymmetry. For example, there are certain 'contact' period Bushman rock engravings and rock paintings in southern Africa that were produced at and after the time of the colonisation of southern Africa by non-Bushmen. Some of the power relations between indigenes and colonists are made explicit in the form of rock-paintings and rock-engravings. Specifically, much of this rock-art shows how the Bushmen imagined and imaged the colonists.
\end{abstract}

\section{Introduction}

A great deal of rock-art research is conducted by people who do not produce rock-art. As a result, much rock-art research concerns itself with how 'we' - the non-rock-artists image 'them' - the rockart producing individuals and communities. This appropriative gaze (cf Said 1989; Eagleton 1990) does have validity within a broadly 'western' postEnlightenment scientific knowledge paradigm. Though fashionable in these post-structuralist times to critique this knowledge paradigm - specifically and justifiably the excesses such as the genocide of indigenous people that it has aided (eg, Blick 1988; Reynolds 2001; Gall 2001), it should be borne in mind that 'western' knowledge can also be empowering. For example, knowledge gained over the last 30 years concerning the sophistication and complexity - even though the terms 'sophistication' and 'complexity' are inevitably measured in our etic frame of reference - of most indigenous rock-art traditions has gone a long way towards overturning debilitating stereotypes of indigenous people as ossified 'children-of-nature' and has helped to rehabilitate their cultural and intellectual status (eg, Lewis-Williams 1995). Knowledge comes in many forms and the world is and has been home to many intellectual traditions. Rock-art, as a polysemous visual artefact, is able to bridge gaps between these intellectual traditions more easily than most other artefacts (cf Elkins 1997). An outsider's understanding of a rock-art tradition is usually best achieved by attempting an a insider's perspective; usually by utilising past and present ethnography relevant to the rock-art producing individual or group (eg, Trigger 1984). One such rock-art tradition is an indelible and provocative part of the southern African landscape. 
For the bulk of its history, southern Africa (fig 1) was the exclusive domain of a diversity of huntergatherer peoples ancestral to the people we today call 'Bushman' or 'San'. It is something of a myth, even among some researchers, that all these gatherer-hunters were parts of a single homogenous entity. Though we speak of 'Bushmen' as a collective - and there were certain overarching beliefs and practices held in common - this is about as useful as speaking of 'the Europeans' as though all the people of Europe share the same customs, languages, territories and so forth. Linguistically, certain of these hunter-gatherer groups were so diverse that some Bushman languages were mutually unintelligible (Traill 1995). Ecologically, these hunter-gatherer groups inhabited areas ranging from deserts, to scrub-savannah, to high mountains, to near rainforest ecotones. Culturally, there also seems to have been great diversity. The many Bushman groups seem to have had a low population density relative to later arrivals and certain parts of southern Africa were barely inhabited (see Deacon \& Deacon 1999 for a summary of Bushman pre-colonial history). This land-wealth contrasted markedly with the situation further north in Africa where herding and farming peoples, especially those around the Great Lakes region, were experiencing severe population pressure and resource stress, forcing certain of these people literally to look for new pastures further south. Based on archaeological excavations, oral histories, glotto chronologies and genetic evidence we know that about 2000 years ago, the first non-Bushmen arrived in southern Africa (eg, Ehret 1998). The autochthonous Bushmen, through their social and gift-exchange networks, would have known of the existence of these farmers and herders, but would have had little direct contact with them. Now their social adeptness and capacity for crosscultural exchange would be comprehensively tested as they, in turn, would test the communicative capacity of the colonists.

There were two macro groups of non-Bushman colonists in southern Africa two millennia ago. One group was a Bantu-speaking farming people with cattle and who planted millet and sorghum. These people were ancestral to the contemporary SothoTswana and Nguni people such as the Sotho, Tswana, Xhosa and Zulu resident in South Africa today. These early farmers had an hierarchically organised, class-based and politically centralised society and believed that the ancestors played an immediate and potent role in daily life (eg, Schapera 1949). They initially moved into southern Africa in small groups following corridors of movement free of tsetse fly (Glossina sp) and settling in the north before moving further into what is now South Africa in western and eastern 'streams' (eg, Huffman 1986). The other macro-group of colonists led a pastoralist, herding way of life with cattle, fat-tailed sheep and goats and are known as the Khoekhoen (formerly 'Khoikhoi' or 'Hottentot'). These people spoke a click language called Khoe that is broadly related to Bushman languages, which today are labeled 'KhoiSan' (see Schapera 1930; Boonzaier et al 1996). The Khoekhoen tended to follow river courses as they migrated through southern Africa and they also intermarried with many Bushman groups, resulting in a degree of cultural and economic homogeneity. Many European colonists had difficulty discerning 'Bushman' from 'Khoekhoen', resulting in confusing textual and pictorial representations of early encounters. Indeed this confusion has been at the centre of the 'Kalahari Revisionist' debate, which questions the longevity of the identity and 'pristine-ness' of especially the Bushmen as observed by the Europeans (see Reid, Sadr \& Hanson-James 1998 for a summary of this complex issue). These Europeans were the third and most recent colonists, physically arriving in South Africa at the Cape of Good Hope in 1652 to establish a halfway stop between Europe and India and the Spice Islands for the Verenigde Oostindische Compagnie (Dutch East India Company).

The complex cultural mosaic of contemporary southern Africa is thus by no means a new phenomenon and has deep archaeological precedent. Southern Africa's colonisation is thus multiple and different to the colonial experiences in places such as Australia and North America, which had, for the most part, a single macro-episode 


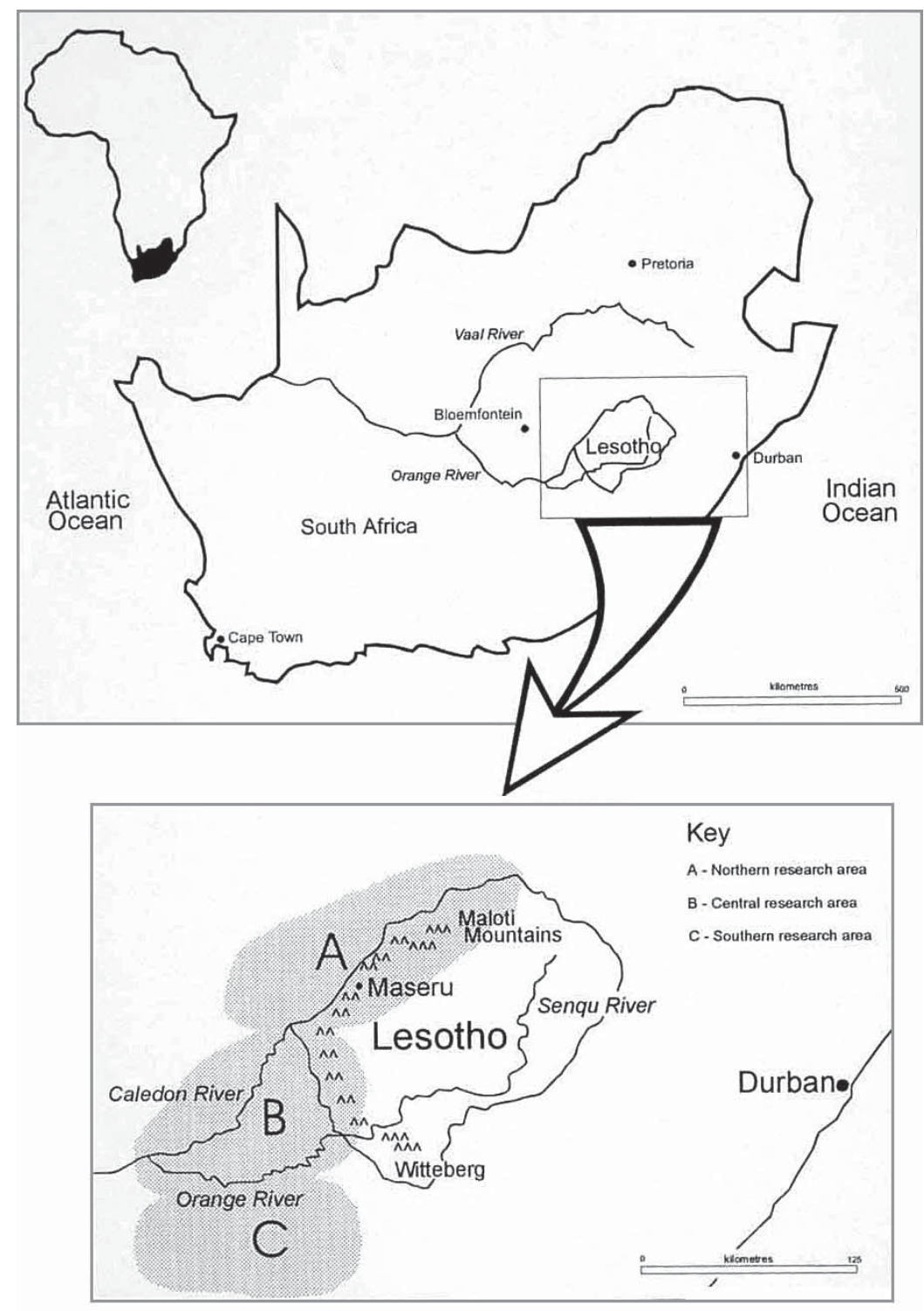

Figure 1 Research areas, southern Africa.

of European colonisation (eg, Jaimes 1992; Mulvaney \& Kamminga 1999:407-424). A further twist to the process of colonisation is wrought by the change in status the passage of time brings. Though originally colonists, the Bantu-speakers and Khoekhoen have, after 2000 years of residence, qualified as 'indigenous' people by most standards, though only the Bushmen have 'First Nation' status. Vigorous debate characterises the question of whether Europeans or 'whites' are or ever will become African indigenes. Having at least four distinct, albeit overlapping cultural groups on a landscape considerably complicates the dynamics of cross-cultural interaction. I now turn to a primary source of evidence of this interaction - rock-art as supported by relevant ethnography to chart the nature of contact between Bushmen and the Bantuspeaking, Khoekhoen and European colonists.

Bushman rock-art has a great deal of supporting ethnography from a variety of sources (see Ouzman 1996:31-40 for a summary of these sources and justification of ethnographic analogy) and this has helped researchers to recognise and appreciate Bushman rock-art as one dominantly of religious and symbolic importance which had ingress into almost every facet of daily Bushman 
life over the last 30,000 years (eg, Vinnicombe 1976; Lewis-Williams 1981; Deacon 1988; Solomon 1992; Ouzman 2001). However, neither the rock-art nor the Bushmen who produced it were static entities. Their shamanistic rock-art was also implicated in the social, political, economic, gendered and other prerogatives of the times. The rock art was one doxic strand that helped Bushmen understand and shape their world. Perhaps the greatest challenge for the Bushmen and their rock-art came with the period of southern Africa's multiple colonisations. Thus, I discuss, by means of 'contact' period Bushman rock-painted image clusters, scenarios of mutual co-operation and respect; a shift in cosmology; the growth of conflict and ideology; an unflattering reverse gaze on Europeans; and an Apocalyptic finale before offering some thoughts on contemporary southern Africa and rock-art research.

Each of the rock painted examples below is drawn from a particular landscape - that of southeastern southern Africa (fig 1). I have chosen this landscape because interaction between Bushmen, farmers, herders and Europeans was intense, multifaceted and protracted. In addition, a great deal of this interaction continued to take place into the ethnographic present, allowing good tie-ins with local histories and the like. Thus, though the physical landscape was the same for everyone in a narrow sense, their relationships to it and actions on it show considerable variation.

\section{Images of co-operation and respect}

Often, people imagine the Bushmen as small, passive and largely helpless people who inevitably gave way to the stronger farming and herding peoples, not to mention the Europeans (eg, Smith 1983). The reality is that for the most part gathererhunter, farmer and herder had cordial relations with each other and respected each other's space. Part of the basis for this goodwill was ecological - each group occupied different areas of the landscape and did not compete excessively for resources. Particularly early on, the colonists were few and often in need of aid from the resident Bushmen. Archaeologically and historically, we are able to pick up inter-group trade, intermarriage and clientship relations (Loubser \& Laurens 1994). The rock-art from this period of early direct contact is still dominantly concerned with Bushman spirituality. I use only imagery that is overtly related to the contact period by virtue of its subject matter. While a coarse-grained understanding of the contact period involves rock-art that has distinct non-Bushman iconographic elements such as domestic animals, images of Bantu-speakers, Khoekhoen, Europeans, non-Bushman weapons such as spears, clubs and guns - there are also apparently 'traditional' images that are deeply implicated in the colonial process. For example, though southern African rock-art dating is very poorly resolved (but see Thackeray 1983; Mazel \& Watchman 1997; Jerardino \& Swanepoel 1999), the more recent-looking Bushman rock paintings of south-eastern southern Africa show a noticeable increase in depictions of serpents and of rain animals. I use the term 'serpent' rather than 'snake' because of their species-indeterminate and often fantastic nature - such as having antelope heads - thus denoting them as Spirit World Beings (fig 2). Such serpents are sometimes depicted as though emerging or entering natural cracks or folds in the rock as a means to show the Bushman belief that one of the places the ever-present Spirit World was located was immediately behind the painted rock face (Lewis-Williams \& Dowson 1990).

Most cultures have beliefs about snakes and this is certainly true of Bushman, Bantu-speakers and the Khoekhoen (eg, Schmidt 1989). Even today, there is a pan-southern African belief in a serpent of enormous size that lives either in a river, deep pool of water, cloud or cave. This serpent is brightly coloured and should be approached very carefully and propitiated lest harm befall individuals, especially young females, and whole communities (Hoff 1998). It would therefore seem as though the serpent and beliefs associated with it acted as a natural conduit for communication between different groups and was one element of the traditional Bushman rock-art repertoire that became emphasised to facilitate intercultural communication. Similarly, rain-animals are 

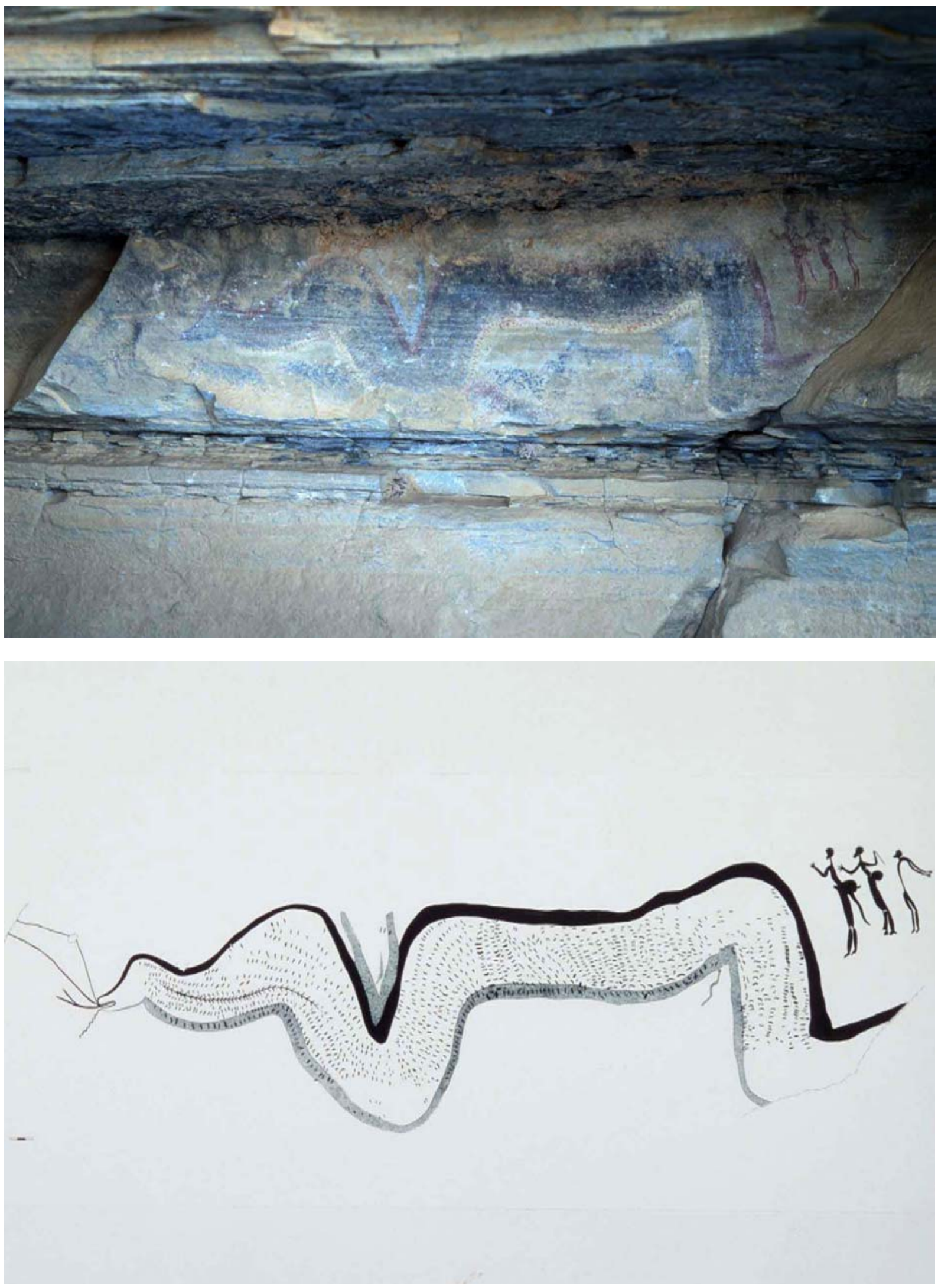

Figure 2a\&b Photograph and redrawing of a Bushman rock-painting of a Spirit World serpent. Black represents red, stipple represents orange and white represents white. Scale bar is $30 \mathrm{~mm}$. 
a distinctive and common feature of Bushman rockart in this south-eastern landscape. Most of these rain-animal rock paintings not only look relatively fresh, they are usually superimposed on top of other imagery, indicating their relatively recent production. Most Bushman communities believed that rain was made by specialist Bushman rain-shamans finding and killing a fantastic - and indeed hallucinatory animal (fig 3) that the /Xam Bushmen called!Khwaka xoro - literally 'water bull/animal' (Bleek 1933). Like serpents, this rain-animal was believed to live in a deep pool of water that was accessible only to the Bushman rain-shamans. Rain-making via the rain-animal thus seems to have been another traditional Bushman belief and practice that was attractive especially to the immigrant farmers, whose livelihood depended so strongly on the weather. Ethnographic sources show that people like the Xhosa regularly employed Bushman rainshamans to ensure good crops and so forth and paid the rain-makers royalties (eg, Prins 1990). Rain-making thus became a commodity over which
Bushmen had strong control and they transacted this commodity with a ready farmer market, enhancing their reputation as masters of the supernatural. Part of this mastery centred on the highly flexible, even idiosyncratic, nature of Bushman religion (eg, Guenther 1999) and its ability to adapt a common as well as idiosyncratic fund of beliefs and metaphors.

\section{A shift in cosmology}

One of these commonly-held beliefs was that a limited set of animals had been imbued by the Great God with an extra-ordinary essence or supernatural potency. Pre-eminent among these potent animals was the eland (Tragelaphus oryx) - the world's largest antelope, weighing up to $900 \mathrm{~kg}$. Credited with a range of meanings and powers, the eland was venerated because it contained a lot of fat. Fat was and is prized by the Bushmen because it is as scarce - most of Southern Africa's game is lean - as it is essential to the physical well-being of hunter-

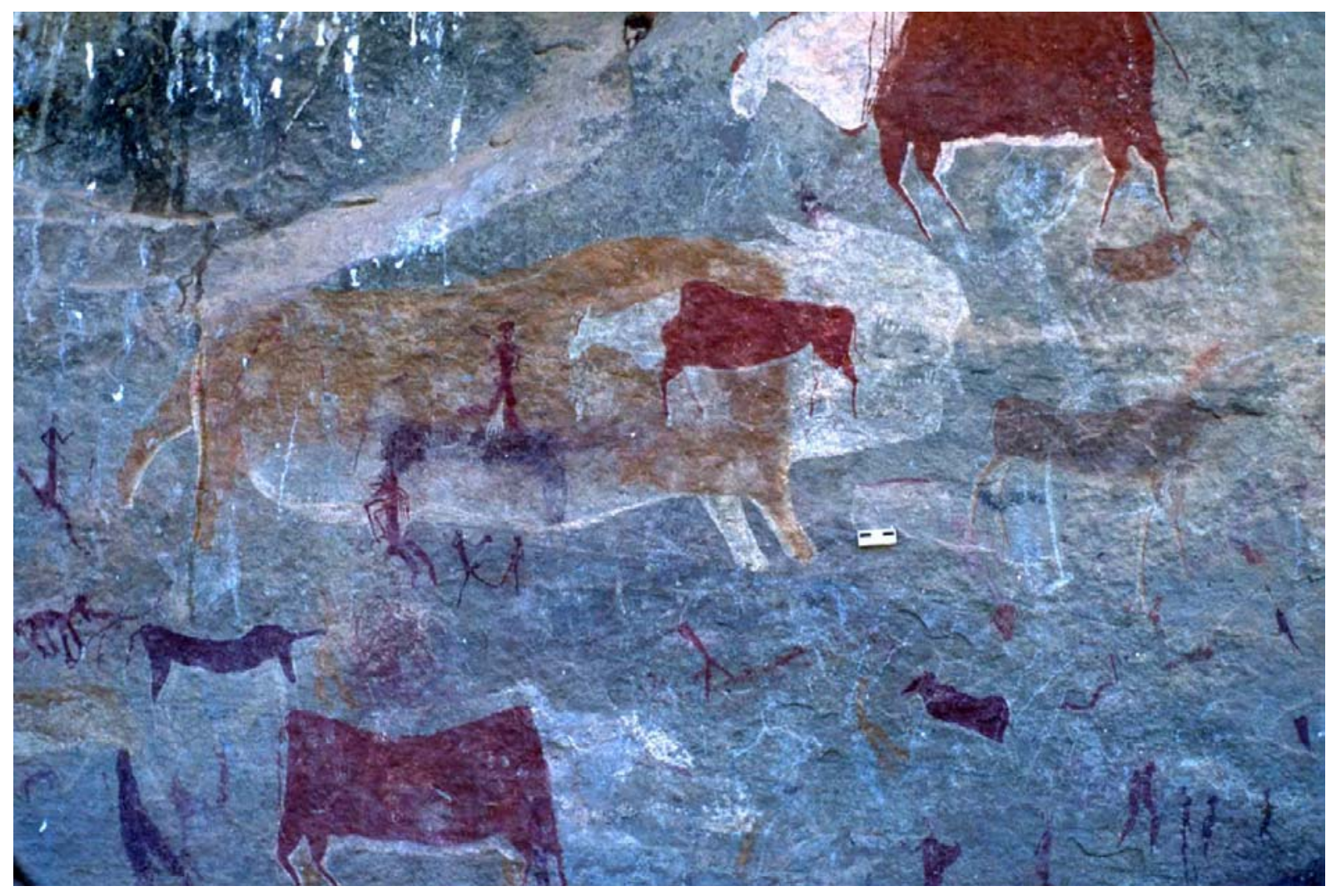

Figure 3 Bushman rock-painting of an hallucinatory rain-animal. Scale bar is $30 \mathrm{~mm}$. 
gatherers (cf Speth 1990). Beyond this physical imperative, it was believed that supernatural potency was found in fat. The celebration of the eland is reiterated many, many times over a vast area in the rock-engravings and rock-paintings of almost all of South Africa and Lesotho. Definite rules applied to painting this animal, for example, it was seldom painted on top of, though it is often painted on top of apparently lesser imagery (eg, Lewis-Williams 1974). Yet, with the impact of colonists over the millennia, the docile but easily frightened and hunted eland's numbers declined and its range shrank. Seeing this process of diminishment, the Bushmen of southeastern southern Africa adopted a proactive strategy whereby they seem to have transferred the qualities and beliefs previously attributed to the eland to another comparable animal - the cow (Bos taurus).

This process of icon replacement is shown in a rock-painting from near the western border of Lesotho (fig 4; see also Dowson et al 1994). A consecutive series of three fine eland are delicately painted in red, white and black paints. Equally delicately painted are the three cattle - each of which is neatly superimposed on top of an eland. This breaking of the usual rules of rock-painting superimposition was not an isolated event that occurred only at this site. Rather, this is a pattern that repeats itself in the more recent rock-paintings of south-eastern southern Africa and suggests a more considered and integrated logic than some act of prehistoric vandalism or rebellion. At a physical level the replacement of eland with cattle makes sense. Both animals are large bovids - the only two exemplars of the uppermost size class that Archaeo-zoologists call 'Bovid 4'. In addition, the spoor (tracks) of eland and cattle are remarkably similar - so much so that even today Bushman trackers have difficulty in distinguishing between the two tracks. Further, both animals have a similar gregarious, docile and herd-like temperament. Also, the habits of both animals are very similar as they both 'blow' - expelling air from their mouths noisily when resting or ruminating. Finally, both animals taste similar with eland having a sweet and most un-game like taste that is remarkably like beef (see Lewis-Williams 1981:106 for further parallels). The cow was thus an ideal candidate as a replacement for the eland and we also find rock paintings in which the two species are conflated into a single depiction (fig 5; see also Ouzman 1997:246-247). The frequency of cattle paintings increases dramatically in more recent times as the cow already an animal of central importance to herders and especially to farmers - started to become an integral part of Bushman beliefs and which they used as an icon familiar to the farmers and herders, but imbued with a supernatural aura emanating from and controlled by the Bushmen.

But in a strange twist of human relations, it seems that veneration as a master of the supernatural also somehow removes one from the contemporary political arena and, increasingly, the Bushmen suffered political marginalisation at the hands of farmers and even herders (Loubser \& Laurens 1994; Hall \& Smith 2001). Part of this marginalisation was inherent in the body politic of indigene and colonists. The Bushmen seem to have had a very localised sense of identity that articulated dominantly with the in-group and localised landscape. This meant that only those Bushmen known to each through kin, social and gift exchange relations considered themselves obligated to each other. Other Bushman groups not tied into this network of social relations were considered as 'other' and almost as unrelated as were farmer and herder groups. In contrast, the farmers and herders were organised along gender and class lines in an hierarchical structure with emphasis on centralised political control. Alliances could thus be formed on a broad base in order to attain a desired objective; to paraphrase a Foucaultian notion (Foucault 1979). Central to this volatile mix of cultural and political differences is land. The Bushmen had a custodial ethos in which they considered the land a vast network of relations and obligations between people, animal, places, spirits and so forth. So vast was this network that no individual or even corporate entity, like a community, could own this landnetwork. Rather, the land or network of relations was believed to own people and govern their actions. In distinction and indeed contradiction to this world-understanding, the Bantu-speaking 

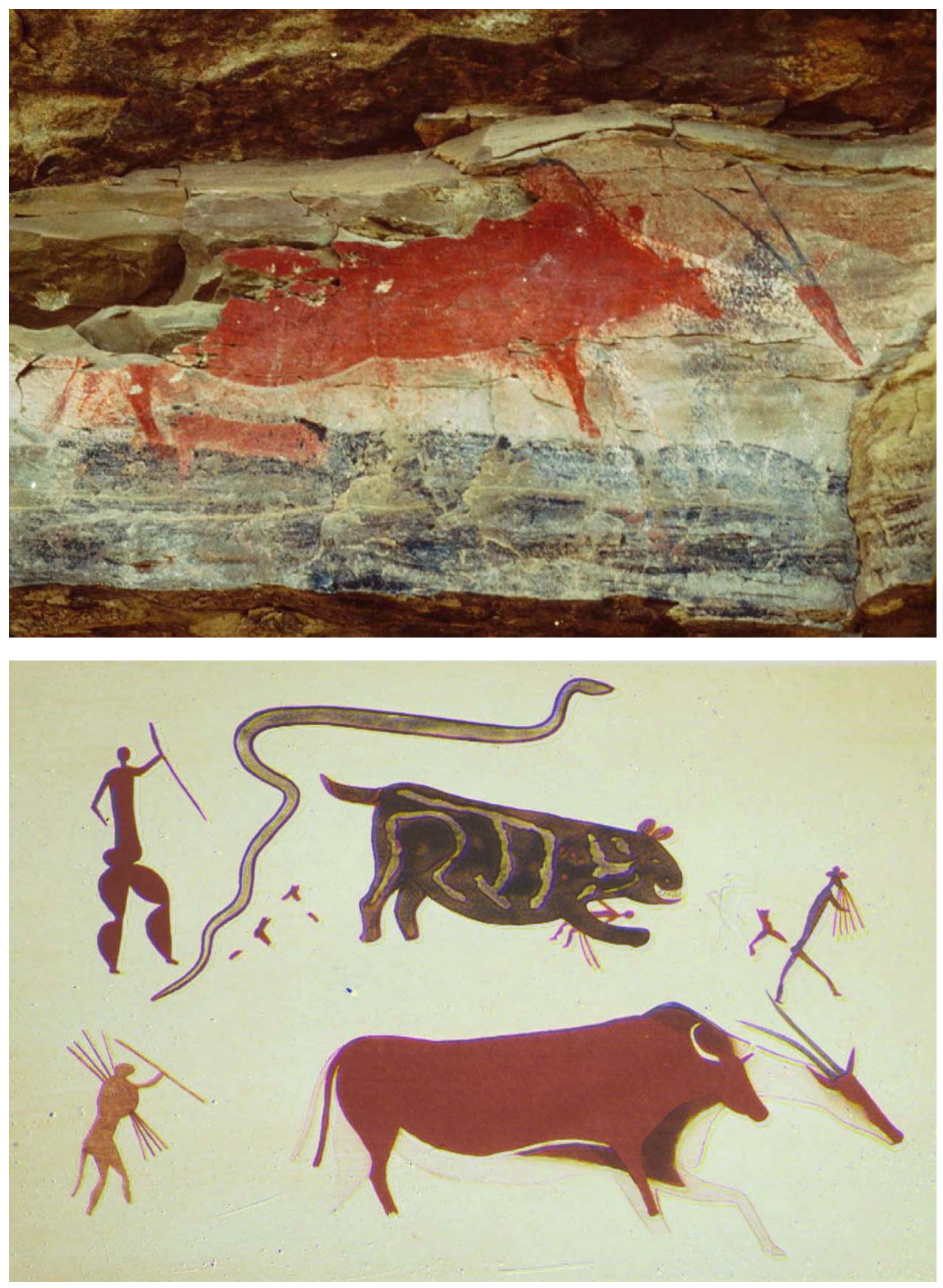

Figure 4a\&b 2000 AD Photograph of a Bushman rock-painting of an eland superimposed by a cow (original length $~ 280 \mathrm{~mm}$ ) juxtaposed with a composite watercolour copy made by George Stow in c 1872 . 


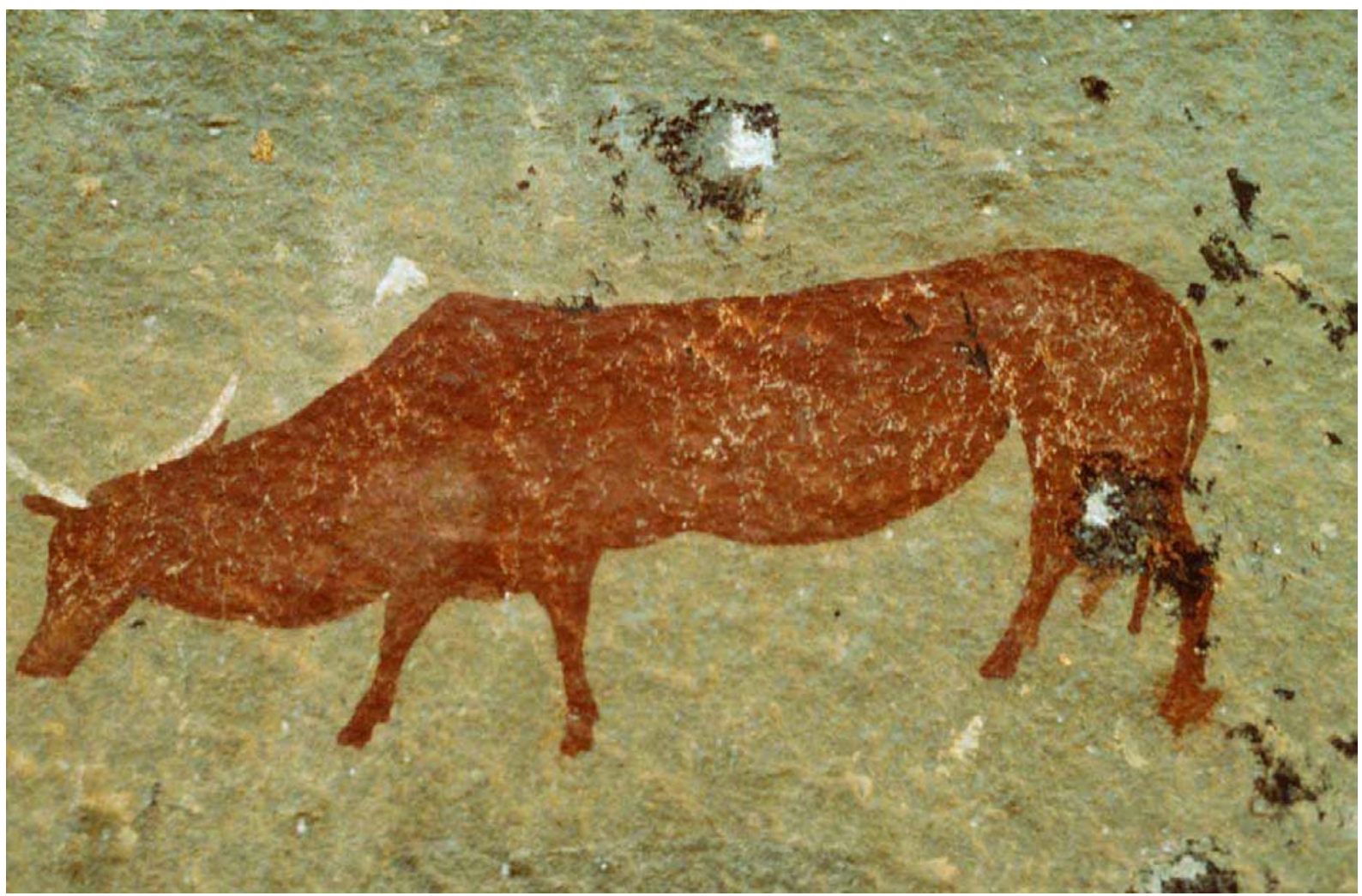

Figure 5 Bushman rock painting that combines the head of a cow with the body of an eland. Black represents red. Length $350 \mathrm{~mm}$.

farmers considered land to be a commodity that was owned exclusively by a community. The Khoekhoen had varying land-understandings but certainly over the last $400-500$ years they too believed in exclusive ownership of land by designated leaders on behalf of a group.

Initially, with low population densities and minimal claim to ecological resources, this contradiction in land usage was masked over, but as the landscape became more populated and people's desire for new commodities increased, so resources became scarcer, and people had to compete more fiercely for them. The traditional transhumant rounds of many Bushman communities, who had a structured physical passage over the landscape determined by the seasons, resources, social obligations and spiritual imperatives, became blocked and impeded by farmer's and herder's homesteads and territories. The tribute initially paid by people like the Sotho farmers to the Bushmen in recognition of their prior custodianship of the land stopped (Callaway 1919) and the wild game on which many Bushman groups depended - as much for self-identification as subsistence - became depleted. Plant foods on which the bulk of the diet depended also became depleted and the gendered activity of mostly women gathering foods unaccompanied and far from home also made them vulnerable to raids and reprisals from non-Bushmen. Here animals constituted another point of friction. Farmers and herders had a binary classificatory system of animals in which sheep, goats and cattle were considered personal and exclusive property but 'wild' animals were considered to be available for everyone's taking. The Bushman also had a binary but fundamentally different classificatory schema for animals - animals of the Spirit World that could be accessed by shamans and rock- art - and animals of the Ordinary World, which they believed came from the Spirit World and which could be used by everyone and could by no means constitute personal property. Thus, the taking of a cow or sheep was not for the Bushmen an act of 'theft' but part of an accepted everyday necessity. 
Intellectually, the Bushmen understood the colonist's concept of personal property and land ownership, but chose to reject it in favour of their own beliefs about animals and land. Of course, such behaviour incensed the stock owners to the point of armed conflict. In some areas, this conflict lasted over 500 years with the Bushmen fiercely defending the places of which they were stewards against people whose status as neighbours had changed to one of guests overstaying their welcome. The ideology of Bushman resistance is captured in a number of rock paintings in southern Africa, notably in places where resistance was protracted.

\section{Ideology and conflict}

The triangle of land between the Caledon and !Garib (Orange) Rivers is a harsh and broken place (fig 1). Marginal for monoculture and suitable for herding only along these two rivers, this area became a refugia or independent enclave for the Bushmen of south-eastern southern Africa. From the relative safety of this place they were able still to trade and interact with their farmer neighbours at a reasonably empowered level. But this resourcepoor region meant that trading also had to be supplemented by the frequent raiding of domestic stock, especially cattle. At least 73 rock paintings in the area depict such stock raids. I take one example from a rock shelter on the banks of the Caledon River. This small, tent-shaped rock shelter provides a useful frame within which to analyse the rock-art imagery structurally. On the northern wall of the shelter there is a collection of over 150 Bushman rock-paintings all executed in paints that are of exotic (30-200 km from source) ferric oxide, fine-grained and which have a deep hue. Subject matter may be classed as 'traditional' with antelope, human figures, a hippopotamus, a remarkable and large twisted serpent, felines and fish. This imagery is formally identical to the majority of Bushman rock-paintings and is classed as 'shamanistic' and being well-integrated with Bushman life in general. In contrast to this corporate and well-understood imagery, the 135 rock-paintings on the southern

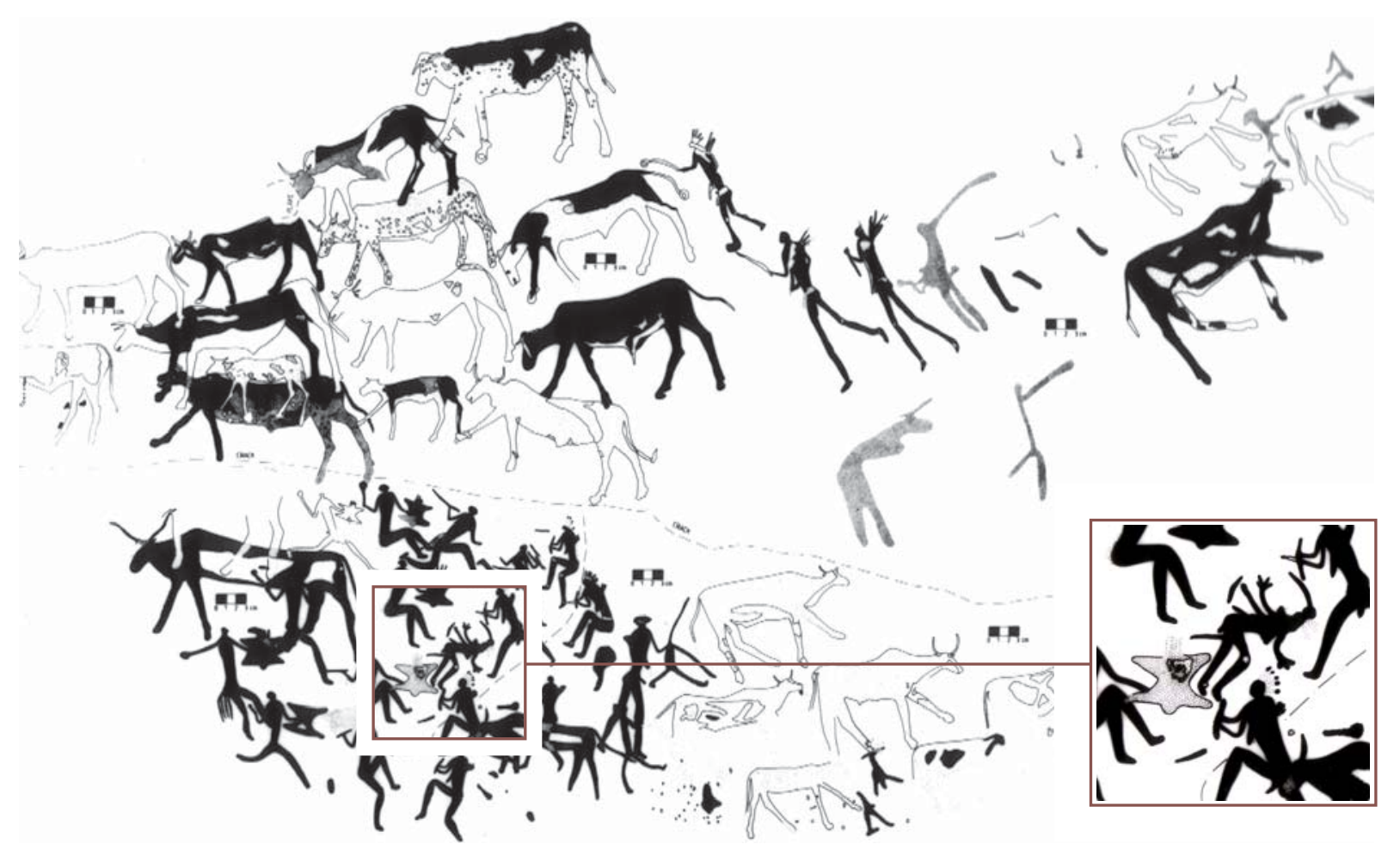

Figure 6 Bushman rock-painting of a cattle raid and battle between Sotho farmers and Bushman bowmen. Black represents red, stipple represents orange and white represents white. Scale bar is $30 \mathrm{~mm}$. 
wall are all explicitly 'contact' in subject matter. Painted in the bright, chalk-like local ferrous oxide pigments we are shown a cattle raid with Bushmen 'stealing' Sotho cattle (fig 6). We can with reasonable certainty ascribe ethnic identity as 'Bushman' and 'Sotho' based on certain iconographic indicators. For example, the anvilshaped objects in four of the six right hand side human figures' hands almost certainly represent the characteristic Sotho shield (van Riet Lowe 1946). Also, the Sotho typically used clubs and spears as weapons, as is shown here. In contrast, the smaller human figures with fuzzy-looking headdresses may be identified as Bushmen. The 'headdresses' are, in fact, a representation of arrows that are filleted in a leather band around the head (bandeau) so as to be instantly ready for quick firing (Berger 1994). Bushmen only ever wore their dangerous poisoned arrows in this fashion when going to war. That this painting is not just a straight narrative rendering of an event is indexed by the centrally-placed and odd-looking human figure that is bending forward and which has nasal and body emissions. These features are all diagnostic of trancing shamans (eg, Lewis-Williams 1987), showing that 'contact' imagery is often a multilayered metaphor incorporating narrative and the symbolic. The layering of such depictions extends also to ideology and even propaganda. For example, none of the 102 known rock-paintings of inter-group conflict from this area can be interpreted as the Bushmen losing the fight and in at least 60 of the conflict clusters the Bushmen are clearly shown as the victors. While they were very good soldiers who had the benefit of local knowledge, we know from recorded sources, including Bushman-derived ones (eg, Stow 1905:103) that Bushmen lost as well as won battles. Rockpaintings such as these are thus not passive reflections of a political and military process, they are integral components of that process, functioning as an enduring visual symbol of Bushman dominance-real or imagined:

We found some very good caves where we got shelter in the rain. Some of them were full of paintings of eland and other sorts of game, battles between Bushmen and Kaffirs, in which the spear and shield seemed somehow always to be giving way to the bow and arrow. History is often not very impartial, and I am afraid our little friends of the cave are no exceptions in their history as represented in the paintings (Bowker in Vinnicombe 1976:94)

The conflict between Bushman, farmer and herder is best characterised as a series of longrunning skirmishes rather than a sustained war between well-defined enemies and all groups continued to live on the same general landscape in their dysfunctional fashion. It was the introduction of European colonists onto this landscape that violently escalated the conflict into one that has resonances even today.

\section{An unflattering portrait of exotic Europeans}

Apart from the occasional shipwrecked crew, southern Africa was first physically colonised by Europeans in April 1652 (fig 7) when the Verenigde Oostindische Compagnie (VOC) or Dutch East India Company decided to establish a provisioning station at the Cape of Good Hope in what is today South Africa. The idea was that their ships en route to and from Asia and the Spice Islands could barter with local Khoekhoen herders for fresh provisions. Initially, this bartering arrangement was mutually beneficial but before long the balance of power

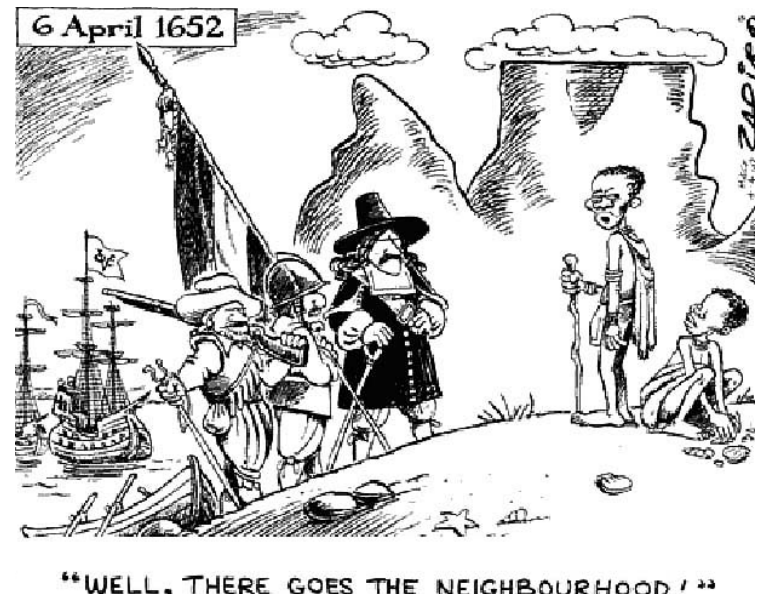

Figure 7 Zapiro cartoon 
shifted decisively in favour of the Europeans who began to expand the refreshment station into a fullblown settlement that is today Cape Town. At this time many people in Europe decided to move to South Africa both to escape repressive social and political conditions and to make a fresh and, they thought, lucrative start in life. Most of these new European arrivals were farmers and they needed land - vast amounts of it. The rapid European expansion into the interior reached south-eastern southern Africa in the early 1800s. The cosmology of the Europeans was unique with most of the Europeans subscribing to the Great Chain of Being (Lovejoy 1936; Gordon 1992) in which all the people of the world were hierarchically grouped one on top of the other in a chain of ascending human superiority based on material richness, technological innovation and divine legitimation. Unsurprisingly, the Europeans placed themselves at the top of this chain and everyone else was slotted in below them. When it came to people like the Bushmen there was considerable debate as to whether they were, in fact, 'people' and thus whether they were even part of the Chain. In whichever event, Bushmen were not regarded by the majority of Europeans as the titleholders of the land the Europeans desired. This status was grudgingly ascribed to Bantu-speakers like the Xhosa and the Sotho, who had similar social and political structures. It was these indigenous farmers' claim to the land that the Europeans sought to disrupt. Initially, treaty and parley were the chosen strategies to acquire land but increasingly violence became the Europeans' stock-in-trade method of operating. It is here insightful to note however, a moment of internal disruption and dissent to this dominant opinion in the form of the early traveller and geologist, George William Stow, who travelled in south-eastern southern Africa in the 1860s and 1870 s and who was one of the few who engaged cordially with the Bushmen. He noted that: "The paintings found in the Bushman caves of the mountains proclaimed the rights and title deeds of the aborigines" (Stow 1905:171). It should be noted that at no time did any European sign a treaty with the Bushmen for 'their' land. Instead, Bushmen were routinely hunted like animals with the men killed and the women and children pressed into indentured service (Gall 2001). This violence and discrimination was observed keenly by the Bushmen. Some of their first paintings of Europeans detailed things such as ox-wagons, which Bushmen at first glance thought were composite animals and were intrigued by their unusual spoor of the draught animals and wagon wheels (cf Skotnes 1993). Other images are more irreverent and mocking - emphasising the voluminous dresses of the European women or the dandy-ish boots of the men.

Perhaps one of the fullest and most nuanced examples of a Bushman portrait of Europeans, and one that offers a sobering 'reverse gaze' is located at the southern end of the Bushman enclave between the !Garib and Caledon Rivers. Slightly above the Little Caledon River is a small and easily overlooked rock shelter that is shielded from view by a large rock bloc across its entrance. The shelter is shallow, less than $1.6 \mathrm{~m}$ high and is about $8 \mathrm{~m}$ long. This site is home to some 87 rock paintings that concentrate in a $1.6 \mathrm{~m} \times 1.1 \mathrm{~m}$ image cluster (fig 8 ). There is very little 'traditional' imagery at this site. Instead there is a fat-tailed sheep painted above a striding human figure bearing three spears and most probably representing a farmer or herder. A few apparently insignificant red finger dots and smears attest to a period when the Khoekhoen used this shelter and left their distinctive finger-painted rock-art (Smith \& Ouzman in press). Separate and to the right of this imagery is a remarkable set of very well-preserved bright, chalky images. At the centre of this image cluster there are two large human figures. The figures are shown in European dress, have their hands placed on their hips near to a powder horn, and each figure has a gun painted next to it. Horses, one with many white dots, flank these two human figures while a third human figure is shown in similar dress with a gun held on its shoulder while dismounting from a striped horse. Immediately below these human figures and horses five lions/lionesses are painted and two of the lions have noticeably bristling manes. As with the Bushman rock-paintings of battles between themselves and farmers, there is a great deal more to this depiction of Europeans than just a narrative observation. In fact, this image cluster 

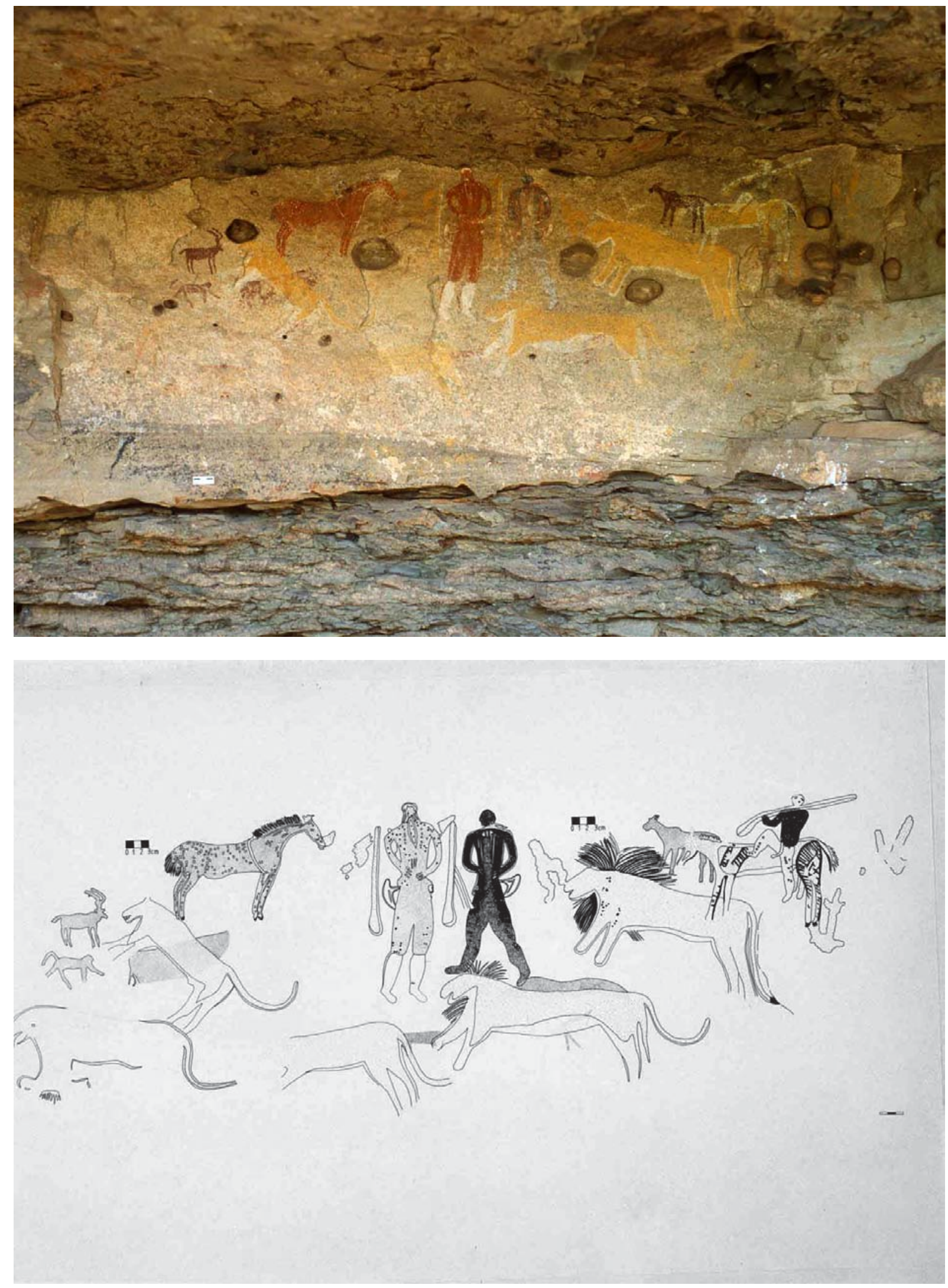

Figure $\mathbf{8} \mathbf{a} \& \mathbf{b}$ Photograph and redrawing of a Bushman rock-painting of European colonists and their horses. Scale bar is $30 \mathrm{~mm}$. 
First, the two central human figures are shown holding their hands on their hips. Human ethology - the study of universal human gestures - suggests that the hands-on-hips or 'teapot' posture is a 'possessive-aggressive' posture that is directed at showing exclusive ownership (Eibl-Eibesfeldt 1989). Alternatively, the human figures could have been painted to show their hands in their pockets - a posture that carries similarly sinister overtures of hiding one's actions/intentions. The painted guns and powder horns painted support this generally aggressive message. Of all the postures and of all the associated items of European material culture that the Bushmen could depict, they selected these, indicating a period of considered observation and interaction that led to this rather unfavourable but not inaccurate characterisation. It is instructive to note that this hand-on-hips posture is found throughout southern African contact period rockart and not just in that of Bushman art. The Northern Sotho, a Bantu-speaking group, have a tradition of protest rock-art in which European women are shown with ultra-short and immodest skirts and men are shown with hands-on-hips (Smith \& LewisWilliams 1998). Intriguingly, other indigenous rockartists such as those in Australia and North America have also singled out this posture as a kind of visual shorthand to signify aggressive and possessive European colonists.

Secondly, the horse painted on the left is covered in fine white dots. The Appaloosa breed of horse has speckles as part of its colouring but these are fairly large and seldom white - usually they are dark spots on a light-coloured coat. In addition, the Appaloosa was only brought into southern Africa in the early-mid twentieth century (Thornton nd; Jinny Martin July 2002 personal communication) and we know that this painting existed by 1842 when townspeople of the nearby settlement of Smithfield reported it to the magistrate Charles Sirr Orpen (Loubser 1993:6). The horse depicted is, based on body shape and size, most likely to represent a Roan or Barb, as these were introduced as far back as 1689, yet neither breed is dappled. Rather than depicting a horse's colouring, a more adequate explanation for the fine white dots is that they represent a re-working of a traditional Bushman visual convention. Bushmen believed in a tangible supernatural essence, called /num by the !Kung Bushmen, that shamans harness and harvest in order to perform the shamanic labours such as healing, rain-making, fighting evil, promoting social harmony and so forth. In southern African rock-art this potency is represented visually by fine white dots and flecs (Dowson 1989). But this supernatural potency is a very powerful thing and only experienced shamans can control it. It has been likened to electricity, both on account of the tingling sensation it induces in people, and also because too much can cause great harm (Marshall 1999:79). The white dots on the horse in figure 8 are far too numerous to represent a safe concentration and function as a type of warning signal. The horse, as a possession of the Europeans and, indeed, one of the means by which they hunted down the Bushmen, has here been marked as something to steer clear of. Similarly, both central human figures have a large quantity of white dots painted on their bodies marking them as beings that were too potent for their own good.

The third level of this image cluster operates in a similar fashion. The pride of lions was not an accidental juxtapositioning of imagery. Rather, they added a further level of aversive denotation. Felines in Bushman thought were traditionally associated with the anti-social, particularly with malevolent shamans, who were believed to assume feline persona and form and marauded around the landscape causing harm to people (Marshall 1999:238). By spatially associating this traditional metaphor with the rock paintings of Europeans, horses, guns and overload of potency dots, the artist(s) who built up this image cluster were examining every facet of the character and behaviour of the Europeans. That at least two of the lions have bristling manes intensifies the texture of impending dread and threat

The fourth level of signification is implicit in the paint used. Locally derived hydrous ferrous oxide $\left(2 \mathrm{Fe}_{2} \mathrm{O}_{3} 3 \mathrm{H}_{2} \mathrm{O}\right)$ has been used to make the paint 
rather than the more prized exotic and deeper hued ferric oxide $\left(\mathrm{Fe}_{2} \mathrm{O}_{3}\right.$ or hematite). This may be because Bushman social networks and trade routes were disrupted, though the area around this painted shelter is vast and rugged, and movement to the high ochre-bearing mountains $10-50 \mathrm{~km}$ distant would certainly have been possible. Rather, it seems more likely that the artists consciously chose to break with tradition and rather than use the exotic pigment used in 'traditional' rock-art, they chose to mark, in bright and local pigment, a new phase in their rock-art - one of political resistance and assertion of their claim to the landscape. Boldly marking their homes, these bright, chalky images are dominantly concerned with images of colonists, conflict and the like, with very little of the 'traditional' imagery here finding expression. An insider's understanding of this panel would have meant a forceful realisation of the contested nature of the landscape.

The contested local landscape is the fifth level in the meaning of these images. This site exists less than 500 metres from a cluster of five Bushman rock-painted shelters, all of which have traditional imagery. These traditional shelters are shallow and open; easily accessible and visible from afar. In contrast, the contact period paintings are placed in a shelter that is hidden and defensible, with a good lookout along the river, which was a natural corridor for colonist's movement. Rock-art imagery and its specific location is thus not happenstance, but was influenced by the dominant socio-political concerns of the day.

The nuanced, multiple and unflattering meanings conveyed in these reverse gaze rock paintings are vital aids in understanding colonialism as a dialectic process. In this case we have the luxury of juxtaposing the rock painting with a European's copy of the same imagery. In 1876, Conolly Orpen, one of the Magistrate Charles Sirr Orpen's seven brothers, made a watercolour copy of the reverse gaze image cluster. Conolly Orpen chose to depict only the three European figures and the two horses, omitting the lions and other details. He was painting what was familiar to him and, being unfamiliar with the meaning of felines in Bushman rock-art, omitted them as being not part of the European composition. He even wrote on his copy: "The whites when they encroached upon bushmanband [sic] little dreamed that there were chiels [archaic $\sim$ young man/boy] about taking notes and painting them." Probably unknowingly, but Orpen was quite right about the Bushmen taking notes on the 'whites' (Europeans) they were surveilling; but he did not have the insider's knowledge to translate these notes that lie so plainly visible on the rock.

\section{Art of the eschaton}

Rather less visible; indeed, almost unnoticed among the many thousands of Bushman rock paintings of south-eastern southern Africa, there is a terminal episode of rock painting. Painted almost exclusively in a watery white pigment on top of all other imagery, there are at least 143 of these rock paintings in 89 sites. These images have, until recently, escaped general observation and explication. A common denominator in this singular painting episode is that the imagery is bizarre, grotesque and distorted (fig 9). Twisted creatures and dog-like creatures endlessly pursuing broken human figures are common. Sourcing cross-cultural research, the most adequate explanation for this very strange imagery is that it is an millenarian apocalyptic or End-Time eschatonic iconography (Ouzman \& Loubser 2000). The bizarreness of the imagery shows how dislocated Bushman relationships with the landscape in general and the Spirit World in particular, have become. The distortion also gives an idea of the sense of personal alienation that the Bushmen of this area suffered. Many of the bizarre beasts depicted may be meant to illustrate potent Spirit World Beings that the Bushmen were trying to coax out from behind the rock so that they may help them vanquish the invaders. The dog-like creatures probably represent the 'dogs of war' created by the Trickster /Kaggen to chase and annihilate the invaders in an ironic twist whereby the invader's dogs are used against them (Orpen 1874:5-6). But the Beings remained firmly locked behind the rock and the dogs of war were not let 
slip so that the groups of Bushmen became ever more dispersed and ever-less numerous until they ceased to exist as a discrete and functioning gatherer-hunter entity on this landscape. The evanescence of these paintings despite their being the most recent imagery captures the sense of jamais $v u$ - the feeling of unfamiliarity in oncefamiliar places - that the Bushmen must have experienced. The message of this final episode in the southern Bushmen's rock-art is as overwhelming as it is depressing. Using the rockart we can chart the resilience and adaptability of Bushman society moving from the spiritual to the political to the end-time. But it should be remembered that this is the history of a specific group of people on a specific landscape. The Bushmen have not ceased to function as a society, though they no longer produce rock-art.

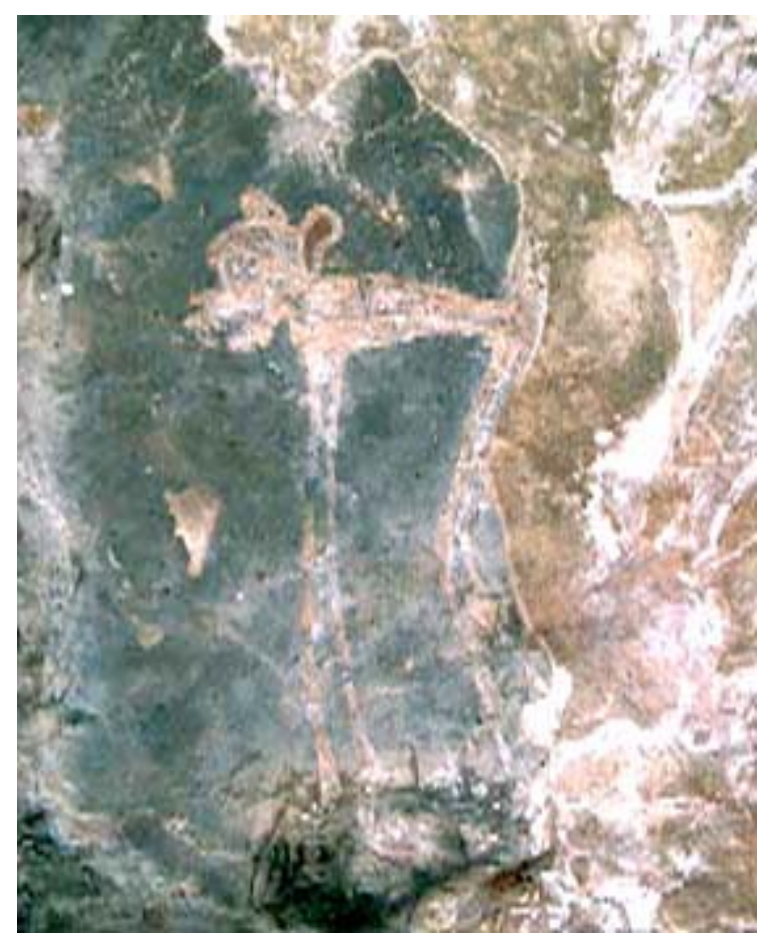

Figure 9 Bushman eschatonic rock-paintings. White represents white. Height $~ 230 \mathrm{~mm}$.

\section{Conclusion}

Although Bushmen no longer produce rock-art, they do retain a spirituality that is closely linked to many of the metaphors encountered in the rock-art. These beliefs, and especially their visual expression are one of the most powerful means of informing ourselves not only about Bushman society, but about non-Bushmen. The irony is that the information flow is still very much from 'them' to 'us' but the type of information so gained is qualitatively different to the usual rock-art research because it tells us as much about who we are and, perhaps more to the point, who we are not, as it does about the rock-artists. The indigenous reverse gaze imagery is also unfettered and uncensored by the mental and iconographic constructions of the colonists. A great deal of post-colonial literature is often quite smug and self-congratulatory choosing often the worst excesses of colonialism. But we also require a more nuanced and dialectical understanding of this process; one that requires 'them' to state their case, albeit often with archaeologists and the like acting as interlocutors (eg, Trigger 1988; Shepherd 1998). For example, consider the contemporary example of Bushman art seen in figure 10. Aesthetically, the piece makes use of strong colour and object contrast, but the full meaning of this visually simple yet politically powerful work is only achieved when the title of the work is known, combining visual and textual literacy (cf Mitchell 1994). It is in Afrikaans - how ironic that the Bushmen have adopted the language of the oppressor as their lingua franca-and is entitled Jagter, eland en minibus, which translates as 'Hunter, eland and taxi'. The Golden Age of the past - when people could hunt - is juxtaposed with the minibus taxi - a pervasive and indispensable part of modern life. That this is more than just an intellectual Bushman musing is demonstrated by its contemporary context. In Botswana, for example, many of the hunting licenses issued to the Basarwa (as the Bushmen are called there) have been revoked. Thus, Botswana's First People are hindered in continuing their 30,000 year-old tradition of hunting. They are not even masters of the land, as they are often forcibly removed from areas owing to the more lucrative imperatives of minerals, tourism and the like. But again, the Bushmen are resilient. Though not really liking the world as it is now, or the neo- 
colonisation of their heritage (eg, Ouzman 1999), they are finding ways to empower themselves. Only last year the !Xun and the Khwe Bushmen, originally from Angola, bought the farm Wildebeestkuil in South Africa's Northern Cape Province. Wildebeestkuil is home to many Bushman rock engravings and now for the first time Bushmen legally own a rock-art property made by their ancestors. Similarly, Bushmen, with aid from nonBushman activists, have asserted their intellectual property over certain plant remedies now used in western aleopathy (Barnett \& Brummer 2001). In many cases, the past is not at all far away from the present and is used daily to empower and to enlighten. The reverse gaze tradition continues in contemporary Bushman art - for those that take the time and who are skilled enough to perceive clearly and to learn.

\section{Acknowledgements}

I thank the James A Swan Fund, United Kingdom; the National Museum, South Africa and the South African Archaeological Society, Kent Bequest, for financial and logistical support. I thank the many landowners and site custodians for permission to access rock-art sites. I thank Ed Eastwood, Paul Faulstich, Dawn Green and Paul Taçon for their critical comments on a draft of this paper.

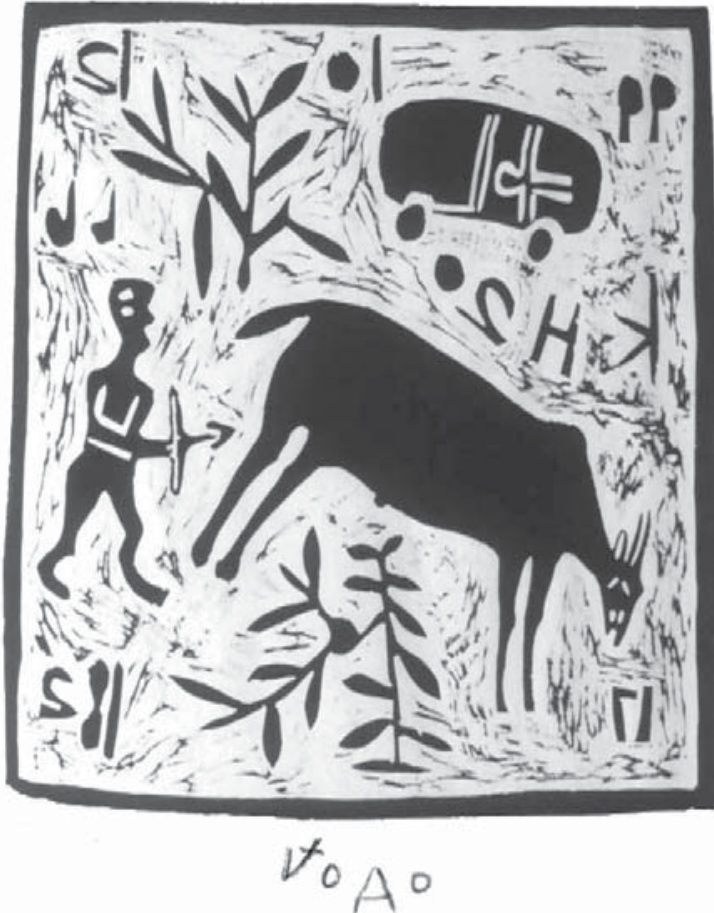

Figure 10 Hunter, eland and taxi. Lithograph by Jaoa Dikuanga 1994.

Thanks also to Jinny Martin for information on the introduction of horses to southern Africa. I thank the Australian Museum's People and Place Visiting Fellowship Scheme for making possible my participation at the AURA 3 conference, at which a draft of this paper was presented.

\footnotetext{
${ }^{1}$ Academics endlessly and rebarbatively debate the validity of the terms 'San' and 'Bushman' for southern Africa's First People. For a summary of these debates see Hitchcock \& Biesele 2000. I use 'Bushman' as a legitimate and honourable term.
} 